\title{
AKSESIBILITAS TATA LETAK ELEVATOR PENUMPANG GEDUNG KANTOR PUSAT LAYANAN TERPADU (KPLT) FAKULTAS TEKNIK UNY
}

\author{
Galeh Nur Indriatno Putra Pratama ${ }^{1}$, Sumarjo $\mathrm{H}^{2}$ \\ 1,2 Jurusan Pendidikan Teknik Sipil dan Perencanan, FT, UNY \\ Email: galeh@uny.ac.id
}

\begin{abstract}
The change of function of KPLT FT UNY Building Hall in the last five years is quite high. In the beginning, the KPLT Building Hall was only to support ospek, yudisium and faculty work meeting. Functions that require the fulfilment of vertical transportation (lift) that is the ceremony dies and syawalan big family of the faculty. The elevator is necessary because the occupation hall is not just people, but also catering equipment for parties. The purpose of this research 1) to determine the capacity of the building elevators KPLT, 2) determine the layout of elevators KPLT building, and 3) the form of the building facade lift KPLT FT UNY. The type of this research is design development, which refers to $4 \mathrm{D}$ Thiagarajan. The results of the study can be shown 1) the elevator capacity for the building KPLT FT UNY is a passenger lift for 10 people, with two doors opening to the side, 2) The location of the FN UNY building elevator UNY in accordance with visibility, accessibility and freeway structure is on the front side east hall, 3) The appropriate elevator support structure for FT UNY building is steel structure because it is an additional construction, while for scopes using GRC, ACP or plastic composite material.
\end{abstract}

Keywords: Accessibility, Elevator layout, KPLT building.

\begin{abstract}
ABSTRAK
Perubahan fungsi Aula Gedung KPLT FT UNY dalam lima tahun terakhir cukup tinggi. Pada awalnya Aula Gedung KPLT hanya untuk mendukung ospek, yudisium dan rapat kerja fakultas. Fungsi yang menuntut pemenuhan sarana transportasi vertikal (lift) yaitu upacara dies dan syawalan keluarga besar fakultas. Sarana lift diperlukan karena okupasi aula bukan hanya orang, namun juga perlengkapan katering untuk pesta. Tujuan kajian ini adalah 1) menentukan besarnya kapasitas lift gedung KPLT, 2) menentukan tata letak lift gedung KPLT, dan 3) bentuk fasad lift gedung KPLT FT UNY. Jenis kajian ini adalah pengembangan desain, dimana mengacu pada $4 D$ Thiagarajan. Hasil kajian dapat ditunjukkan 1) kapasitas lift untuk gedung KPLT FT UNY adalah lift penumpang untuk 10 orang, dengan dua pintu membuka ke samping, 2) Letak lift gedung KPLT FT UNY yang sesuai dengan visibilitas, aksesibilitas dan bebas hambatan struktur adalah di sisi depan sebelah timur ruang hall, 3) Struktur pendukung lift yang sesuai untuk gedung KPLT FT UNY adalah struktur baja karena merupakan konstruksi tambahan, sedangkan untuk pelingkupnya menggunakan GRC, $A C P$ atau bahan komposit dari plastik.
\end{abstract}

Kata kunci: Aksesbilitas, Tata letak elevator, Gedung KPLT.

\section{PENDAHULUAN}

Kantor Pusat Layanan Terpadu (KPLT) FT UNY memiliki fungsi pelayanan terpadu bagi civitas akademika FT UNY. Layanan terpadu mencakup: layanan akademik, layanan kegiatan kemahasiswaan, layanan administrasi keuangan dan kepegawaian, dan layayan umum lainnya. Gedung ini didirikan pada tahun 2004 dan selesai dibangun tahun 2006 dan resmi dipakai pada awal tahun 2007. Dalam kurun penggunaan sepuluh tahun terakhir, fungsi makin beragam seiring

meningkatnya aktifitas mahasiswa dan lembaga terkait. Kegiatan seminar padat setiap tahun, kegiatan pertemuan besar juga meningkat setiap tahun. Semua kegiatan besar tersebut ada pada lantai tiga gedung yaitu pada ruang aula yang berkapasitas 700 orang.

Sementara itu dalam aktifitas sehari-hari, suatu pekerjaan atau pelayanan, orang membutuhkan suatu alat untuk dapat mengefesienkan waktu, tenaga, biaya dan 
percepatan suatu pekerjaan atau pelayanan pada gedung bertingkat. Disamping itu, pada saat ini pelayanan difabel dalam suatu gedung menjadi wajib disediakan oleh gedung tersebut. Hal ini membawa kosekuensi perlunya menyediakan lift untuk melayani para difabel ke lantai tiga. Oleh karena itu sangat dibutuhkan lift untuk mendukung transportasi vertikal pada gedung KPLT FT UNY.

Permasalahan yang diakibatkan dengan adanya penambahan lift penumpang/barang di Kantor Pusat Layanan Terpadu (KPLT) Fakutas Teknik Universitas Negeri Yogyakarta adalah terkait dengan aksesibilitas letak lift dan kapasitas lift pada bangunan. Penempatan lift penumpang/barang akan mempengaruhi akses lintasan kemudahan dan keamanan pengguna, sehingga perlu dilakukan perancangan tata letak lift agar dihasilkan desain yang optimal.

Secara umum, tujuan dari kajian ini adalah sebagai berikut: 1) menentukan besarnya kapasitas beban/penumpang lift yang diperlukan pada gedung KPLT FT UNY, 2) mendesain konfigurasi tata letak lift gedung KPLT yang optimum, dan 3) mendesain konfigurasi bentuk lift dan fasad gedung KPLT FT UNY.

Sirkulasi adalah pergerakan yang menghubungkan ruang-ruang dalam suatu bangunan atau suatu deretan ruang dalam dan ruang luar secara bersama. Brubaker (2008), berpendapat sirkulasi merupakan unsur yang dapat mempengaruhi kita tentang bentuk dan ruang dari bangunan. Kita merasakan ruang saat kita berada didalamnya dan ketika kita menetapkan tempat tujuan. Dalam proses tersebut ada waktu perpindahan, melalui tahapan dari dan ke ruang.

Pendekatan konsep sirkulasi berdasarkan pada: 1) hirarki dan variasi konfigurasi jalur pergerakan, umumnya pergerakan akan mencari jalur pergerakan, umumnya pergerakan akan mencari jalur yang paling cepat dan paling mudah, kecuali ada halhal yang mempengaruhinya, seperti pengalaman visual, pengalaman ruang , dan lain-lain, 2) penciptaan suasana yang mendukung pergerakan (berkaitan dengan penyinaran, tekstur, material, dan polapola serta merangsang pergerakan dan menghindari lelah dan jenuh), 3) adanya hubungan fisik maupun visual yang baik antara ruang dalam dan ruang luar, 4) penciptaan suatu titik perhatian (point of interest) sebagai faktor pengarah dan orientasi.

Sirkulasi antar ruang memiliki pengertian Kita bergerak dalam waktu, melalui suatu tahapan, dan di dalam ruang. Kita merasakan suatu ruang dalam hubungan di mana kita berada dan ke mana kita menetapkan tujuan. Sirkulasi menghubungkan ruang satu dengan ruang lainnya. Sirkulasi dapat menggunakan ruang yang sudah ada atau memiliki ruang sirkulasi sendiri (Hartono, 2012).

Adapun beberapa bentuk hubungan jalan dan ruang, antara lain 1) melewati ruang, integritas ruang dapat dipertahankan, konfigurasi jalan, luwes, ruang-ruang perantara dapat dipergunakan untuk menghubungkan jalan dengan ruang, 2) menembus ruang, jalan dapat menembus ruang menurut sumbunya, miring, atau sepanjang sumbu; dalam memotong ruang, jalan menimbulkan pola-pola istirahat dan gerak didalamnya, 3) berakhir dalam ruang, lokasi ruang menentukan jalan; hubungan jalan-ruang digunakan untuk mencapai dan memasuki secara fungsional atau melambangkan ruangruang penting (Dibner, 2015).

Adapun beberapa bentuk sirkulasi, antara lain: 1) tertutup, membentuk galeri umum atau koridor pribadi yang berkaitan dengan ruang-ruang yang dihubungkan melalui pintu-pintu masuk pada bidang 
Aksesibilitas Tata Letak ... (Sumarjo/ hal. 26-35)

dinding, 2) terbuka pada salah satu sisinya, membentuk baikon atau galeri yang memberikan kontinuitas visual dan kontinuitas ruang dengan ruang-ruang yang dihubungkannya, 3) terbuka pada kedua sisinya, membentuk deretan kolom untuk jalan lintas yang menjadi sebuah perluasan fisik dari ruang yang ditembusnya.

Beberapa jenis konfigurasi jalan yang dijadikan pedoman, antara lain: 1) linier, jalan yang lurus dapat menjadi unsur pengorganisir utama deretan ruang, jalan dapat berbentuk lengkung atau berbelok arah, memotong jalan lain, bercabangcabang, atau membentuk putaran (loop), 2) radial, konfigurasi radial memiliki jalanjalan lurus yang berkembang dari sebuah pusat bersama, 3) spiral (berputar), suatu jalan tunggal menerus yang berasal dan titik pusat, mengelilingi pusatnya dengan jarak yang berubah, 4) grid, konfigurasi grid terdiri dari dua pasang jalan sejajar yang saling berpotongan pada jarak yang sama dan menciptakan bujur sangkar atau kawasan ruang segi empat, dan 5) jaringan, konfigurasi yang terdiri dari jalanjalan yang menghubungkan titik-titik tertentu dalam ruang.

Pada kenyataannya sebuah bangunan umumnya membuat konbinasi dari polapola di atas (Prihadi, 2017). Hal terpenting dalam setiap pola adalah pusat kegiatan, jalan masuk ke ruangan, serta tempat untuk sirkulasi vertical, guna menghindari timbulnya orientasi yang membingungkan, suatu susunan hirarkis di antara jalur-jalur dan titik bangunan dapat dibangun dengan membedakan skala, bentuk, panjang, serta penempatannya.

Lift adalah angkutan transportasi vertikal yang digunakan untuk mengangkut orang atau barang. Lift umumnya digunakan di gedung-gedung bertingkat tinggi; biasanya lebih dari tiga atau empat lantai. Gedunggedung yang lebih rendah biasanya hanya mempunyai tangga atau eskalator. Lift-lift pada zaman modern mempunyai tomboltombol yang dapat dipilih penumpangnya sesuai lantai tujuan mereka, terdapat tiga jenis mesin, yaitu Hidraulic, traction atau katrol tetap, dan Hoist atau katrol ganda. Jenis hoist dapat dibagi lagi menjadi dua bagian, yaitu hoist dorong dan hoist tarik. Elevator adalah alat transportasi vertikal yang biasa digunakan pada bangunan tinggi, berupa box/cabinet yang dapat digerakkan naik turun perlantai sesuai kehendak dengan cara elektromekanik. Poerbo (2012) menjelaskan, elevator berdasarkan fungsinya dibedakan: passenger elevator, elevator penumpang; freight elevator, elevator barang; service elevator, elevator Service.

Berdasarkan penggunaannya, Lift dibedakan 4 kelompok antara lain: passenger elevator, observation elevator, service elevator, fireman elevator. Berdasarkan dari bentuknya, lift dibedakan menjadi 4 kelompok yaitu: lift penumpang, lift penumpang (yang transparan), lift untuk rumah sakit, dan lift untuk kebakaran atau barang.

Poerbo (2012) berpendapat, istilah yang sering digunakan dalam konstruksi lift: 1) drive Shave: roda utama yang ada pada mesin/motor lift; 2) counterweight: Bobot imbang untuk mengimbangu beta sangkar; 3) counterweight Rail: Rel untuk memandu jalannya bobot imbang; 4) sangkar (car): sangkar tempat berdiri penumpang naik turun; 5) traveling distance: jarak gerak dari lantai palin bawah sampai lantai paling atas dalam kondisi operasi normal; 6) guide rail: Rel pemandu untuk agar sangkar bisa berjalan vertikal tidak berayun dan sebagai sarana untuk pengeraman darurat; 7) door operator: pengatur buka- tutup pintu lift, dan 8) controller: pengontrol kerja elevator.

Julistiono (2013) berpendapat, jumlah lift pada gedung ditentukan dari analisis aspek-aspek: (1) jenis gedung, (2) round trip, (3) kapasitas lift, (4) kecepatan lift, 
dan (5) zonasi tingkat gedung. Beban puncak lift tergantung: jenis gedung dan lokasi gedung. Persentase besarnya penghuni kantor di Indonesia, antara lain: kantor $4 \%$ dari jumlah penghuni gedung, flat 3\% dari jumlah penghuni gedung, hotel $5 \%$ dari jumlah penghuni gedung, RS 5\% dari jumlah penghuni gedung. Taksiran kepadatan pengguna gedung per $\mathrm{m}^{2}$ : perkantoran $4 \mathrm{~m}^{2} /$ orang; flat $3 \mathrm{~m}^{2} /$ orang; hotel $5 \mathrm{~m}^{2} /$ orang.

Waktu yang diperlukan lift berjalan bolakbalik dari lantai terbawah hingga teratas (dalam zone), termasuk waktu berhenti, pemumpang keluar masuk lift dan pintu membuka dan menutup di setiap lantai tingkat, dengan kapasitas " $m$ " orang (Julistiono, 2013) dirinci sebagai berikut: penumpang masuk lift di It dasar $=1.5^{\star} \mathrm{m}$ detik/orang; pintu lift menutup di lantai dasar $=2$ detik; pintu lift membuka dan menutup di setiap lantai $=(n-1)^{\star} 2$ detik; penumpang keluar per lantai $=\{(\mathrm{n}$ $\left.1)^{*} \mathrm{~m}\right\} /\left\{(\mathrm{n}-1)^{*} 1.5\right\} \quad$ detik $=1.5^{*} \mathrm{~m}$ detik; perjalanan bolak balik lift (dasar ke atas) $=$ $\left(2(n-1)^{\star} h\right) / s$ detik; pintu lift membuka di lantai dasar $=2$ detik.

Penentuan kapasitas Lift harus direncanakan dengan mempertimbangkan

\section{METODE}

Kajian ini merupakan Research and Development (R\&D). Objek Kajian meninjau tata letak yang optimum ruang lift gedung KPLT FT UNY. Desain kajian disesuaikan dengan Thiagarajan (1974) yaitu 4D models. (1) pendefinisian (define) (2) Perancangan (design) (3) Pengembangan (develop) (4) Penyebaran (disseminate). Define yaitu pendefinisian awal, mencakup kegiatan jumlah okupasi, ruang eksisting dan identifikasi jenis lift. Design yaitu perancangan terkait aspekaspek: analisis okupasi, optimasi letak, kondisi waktu puncak dimana terjadi konsentrasi penumpang tertinggi (Brubaker, 2008). Disarankan: untuk gedung kecil sampai menengah, kapasitas passanger $\geq 15$ penumpang load capacity of $1000 \mathrm{~kg}$ ), untuk gedung tinggi/hotel, kapasitas passanger $\geq 24$ penumpang (load kapacity of $1600 \mathrm{~kg}$ ).

Dibner (2015) dapat dijelaskan, pintu lift sebaiknya didesain terbuka dari tengah dan ukuran lebar ruang masuk disarankan selebar mungkin dengan tetap mempertimbangkan ukuran dimensi kedalaman ruang elevator.

Waktu yang dibutuhkan untuk bergerak dari lantai paling atas ke lantai paling bawah tidak lebih dari 30 detik. Berikut ini dasar pemilihan kecepatan elevator: kecepatan dipilih tergantung tinggi gedung; makin tinggi gedung, makin cepat lift; kecepatan mempengaruhi waktu bolak-balik lift, waktu menunggu lift, sebagai batas kecepatan diambil gerak jatuh bebas oleh gaya tarik bumi (10 $\mathrm{mtr} / \mathrm{dt}$ ), kecepatan tinggi lift mendekati 10 $\mathrm{mtr} /$ detik. penentuan jenis lift dan perhitungan jumlah lift. Develop yaitu pengembangan terkait pembahasan melalui seminar hasil untuk mendapat masukan dari ahli dan pemakai (penilaian ahli dan uji coba pengembangan rancangan). Disseminate (diseminasi) yaitu pengembangan rancangan dalam gambar detil (DED).

Data-data yang kajian yang diperlukan mencakup: jumlah okupasi gedung reguler dan laten, bentuk ruang dan fungsi eksisting, jenis lift yang dapat 
dipergunakan, bentuk struktur lantai gedung. Teknik pengumpulan data melalui observasi, dokumentasi dan wawancara.

Analisis data dengan teknik: daftar uji, matrik dan amalgamasi. Model matrik optimasi desain, evaluasi dan amalgamasi menggunakan model Leopold dengan pertimbangan dapat merangkum lintasan dan skor penting dalam pendekatan desain.

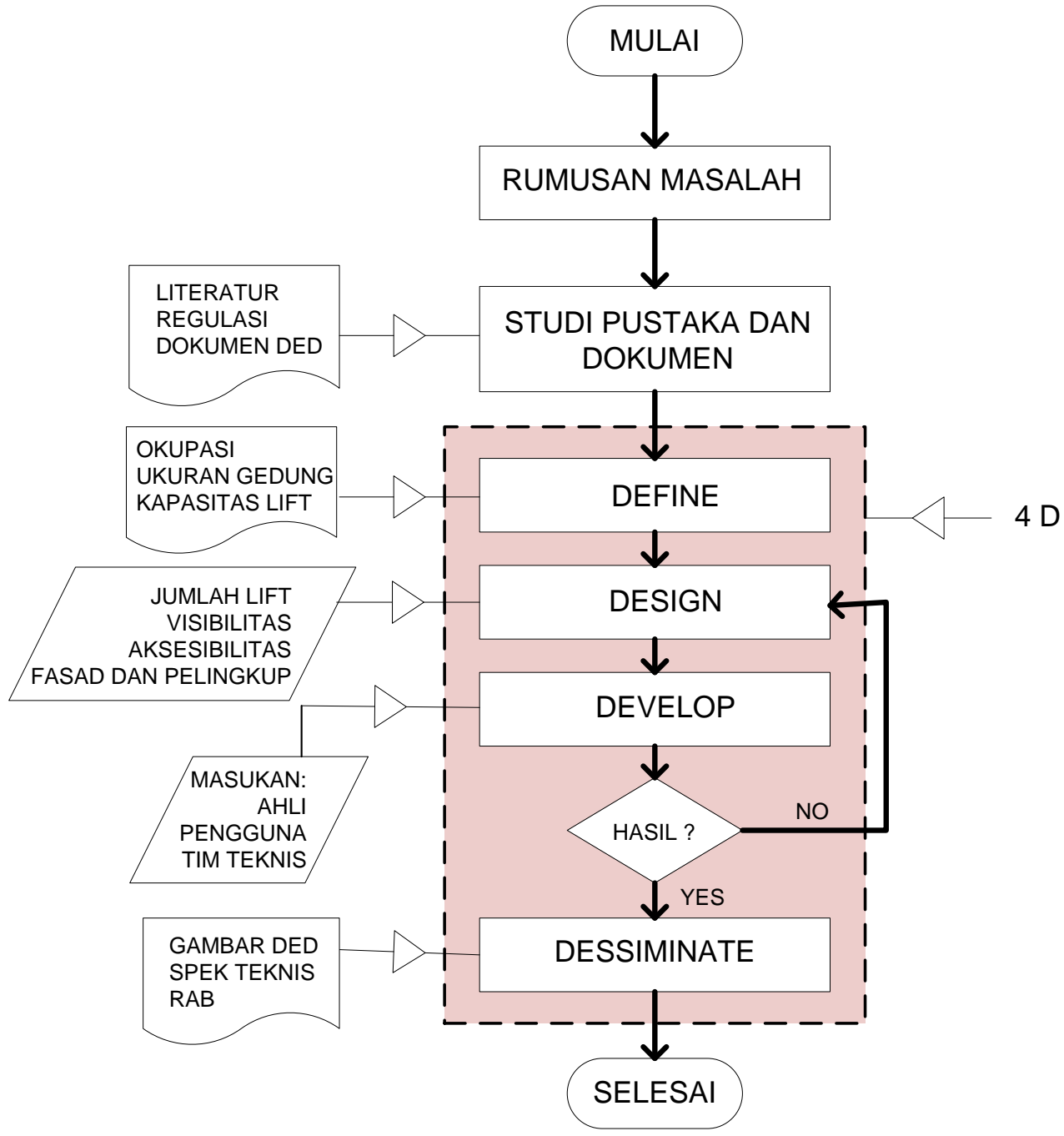

Gambar 1. Diagaram Alir Pelaksanaan Kajian

\section{HASIL DAN PEMBAHASAN}

Data yang diperoleh dari perjalanan bolak balik (trip) untuk sirkulasi orang adalah 32 menit dan untuk barang 122 menit. Namun demikian, yang lebih diperhatikan adalah faktor kelelahan yang tinggi untuk orang yang membawa barang. Sementara untuk okupasi orang yang menjadi perhatian adalah orang lanjut usia, ibu-ibu dan anakanak. Sedangkan untuk okupasi laten adalah para difabel dan orang yang 
sedang cedera kaki. Hasil observasi okupasi dan sirkulasi berdasar data dan fakta lapangan merekomendasikan perlunya melengkapi gedung KPLT FT UNY dengan alat transportasi vertikal (elevator).

Luas fungsional adalah luas lantai gedung yang efektif digunakan untuk fungsi kegiatan, sementara luas ruang untuk perawatan gedung diabaikan. Luas funsional gedung KPLT berdasar observasi kegiatan puncak adalah $686 \mathrm{~m}^{2}$ (14x49m). Kegiatan tertinggi (puncak) yang memerlukan sarana transportasi vertikal di gedung KPLT adalah acara dies institusi dan syawalan. Luas efektif per pemakai ruang sebagai dasar perhitungan kapasitas elevator yaitu: luas ruang fungsional dibagi jumlah pengguna ruang, yaitu: $686 \mathrm{~m}^{2}$ dibagi 750 orang menjadi $0,92 \mathrm{~m}^{2}$ per orang.

Kapasitas dan Kebutuhan Elevator Gedung KPLT FT UNY: $M=$ (a'nwP)/(300a") adalah sebesar 9,05. Jadi dipilih lift dengan kapasitas penumpang 10 orang. Sedangkan waktu perjalanan bolakbalik dengan lift sebesar 40,67 detik.

Aksesibilitas elevator (lift) dirancang dalam 4 kriteria letak, sesuai bentuk gedung sekitar lobi lantai satu. Analisis kriteria dilakukan oleh tim ahli peneliti dan divalidasi oleh ahli dan pemakai. Lokasi 4 di bagian belakang barat gedung cukup visibel namun jauh dari pintu masuk utama dan pelubangan lantai akan merusak jaringan pipa. Lokasi 3 di bagian belakang timur gedung cukup visibel, dekat pintu servis, namun jauh dari pintu masuk utama dan pelubangan lantai juga akan merusak jaringan pipa. Pada lokasi 2, yang ada pada bagian depan barat gedung sangat visibel, namun jauh dari pintu servis, dan pelubangan lantai memungkinkan. Pada lokasi 1, yang ada pada bagian depan timur gedung sangat visibel, dan tidak terlalu jauh dari pintu servis, dan pelubangan lantai memungkinkan. Jadi lokasi terbaik (optimum) lift dekanat FT adalah pada lokasi 1, yaitu bagian depan timur gedung.

Adapun masukkan untuk lokasi lift yang lain yaitu di bagian luar depan atau belakang gedung agar tidak melubangi lantai, namun demikian, secara arsitektural lokasi di luar gedung dapat mengganggu keseimpangan estetika gedung.

Kriteria fasad (wajah) ruang lift antara lain: menyatu (unity) dengan wajah gedung, yang dapat diujudkan dengan bentuk geometrik, warna, dan aksesoris pelengkapnya; menarik perhatian (aksen) daripada ruang yang lain, misalnya ada gate yang melingkupi, ada sabuk dan lampu yang menerik perhatian; bahan pelapisnya kedap air dan kedap gores, misalnya lapis granit, marmer, bahan komposit dan kayu melamin.

Struktur pendukung lift harus tahan benturan dan getaran, pada umumnya dari struktu beton bertulang. Struktur baja dapat digunakan dan dibuat konstruksi pelingkupnya yang tahan benturan dan getaran misalnya dari balan pelat logam. Apabila menggunakan bahan tembus pandang seperti kaca, harus cukup tebal dan ada penjepit kaca yang tahan bentur dan getar.

Hasil review gedung KPLT, struktur pendukung lift yang paling cocok adah struktur baja karena gedung sudah eksisting, sedang lift adalah komponen tambahan. Pelingkupnya dapat dikonstruksikan dari bahan GRC, ACP dan kaca yang cukup tebal. Dari contoh desain yang ditampilkan pada gambar 7 , desain 2 paling sesuai untuk fasad dan pelingkup lift gedung KPLT. Dilihat dari struktur 
konstruksi baja dan pelingkupnya desain 2 gedung eksisting.

unity dengan konstruksi lift dan lingkungan

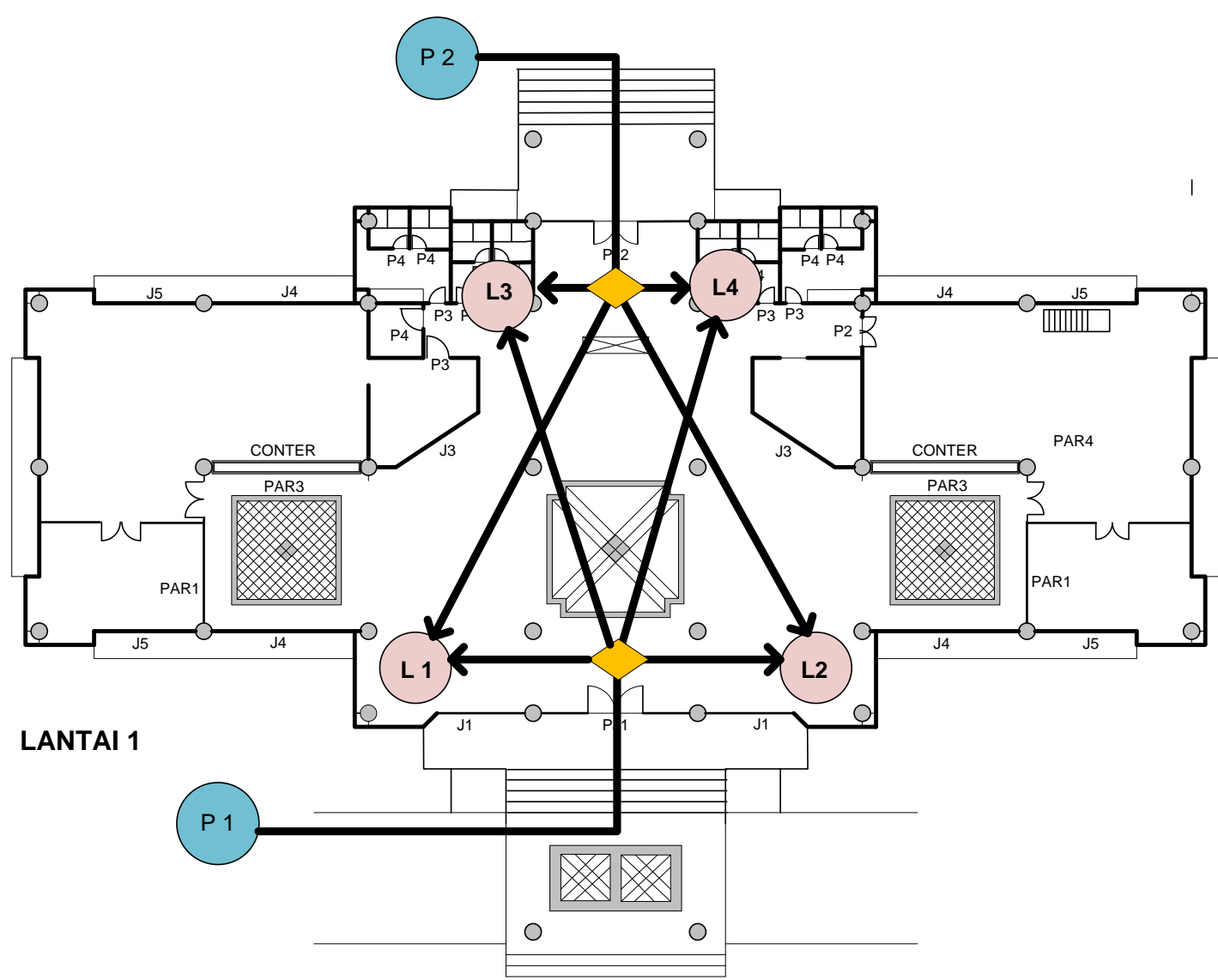

Gambar 2. Visibilitas dan Aksesbilitas

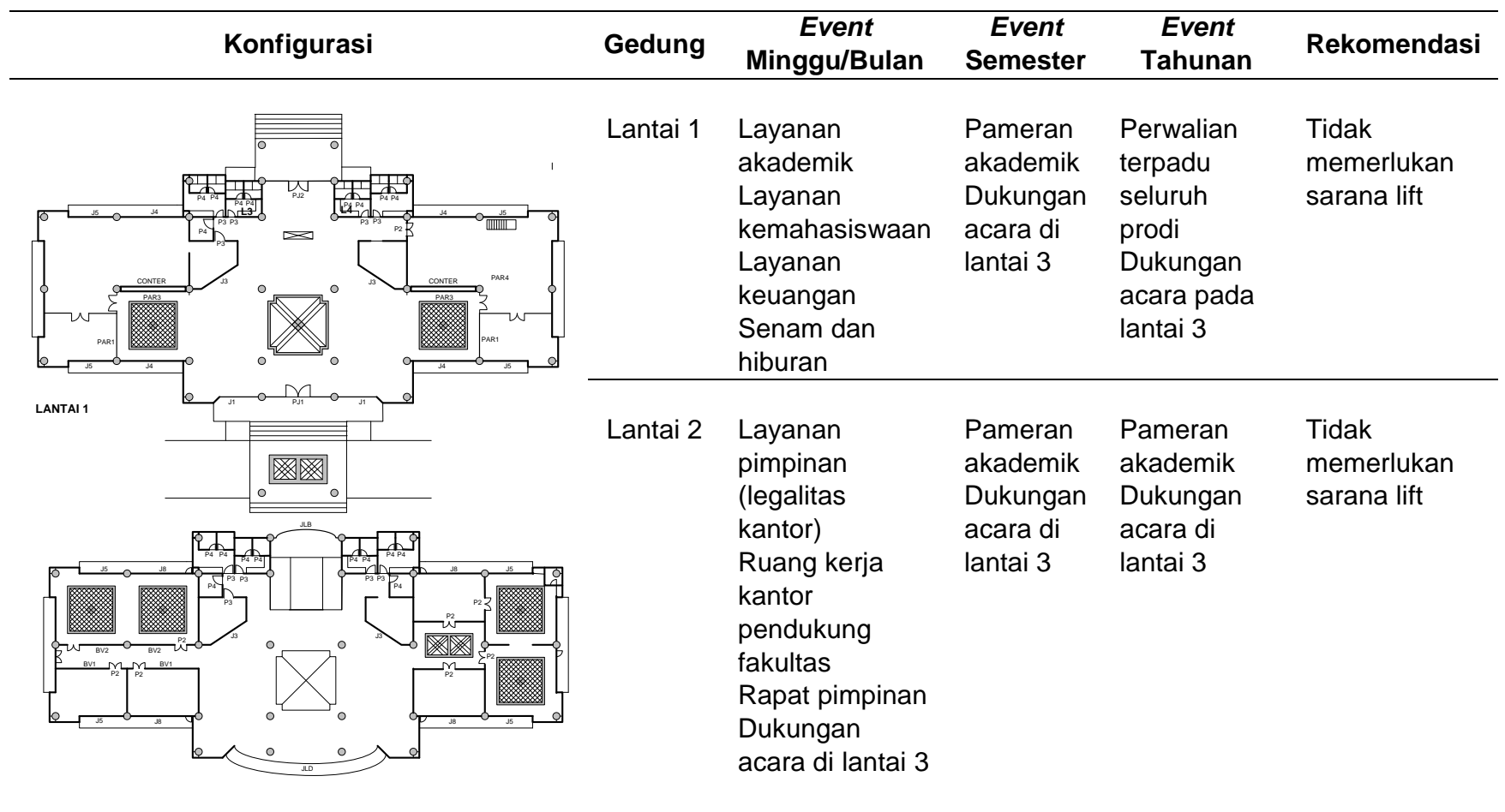


Aksesibilitas Tata Letak ... (Sumarjo/ hal. 26-35)

\begin{tabular}{|c|c|c|c|c|c|}
\hline Konfigurasi & Gedung & $\begin{array}{c}\text { Event } \\
\text { Minggu/Bulan }\end{array}$ & $\begin{array}{c}\text { Event } \\
\text { Semester }\end{array}$ & $\begin{array}{c}\text { Event } \\
\text { Tahunan }\end{array}$ & Rekomendasi \\
\hline 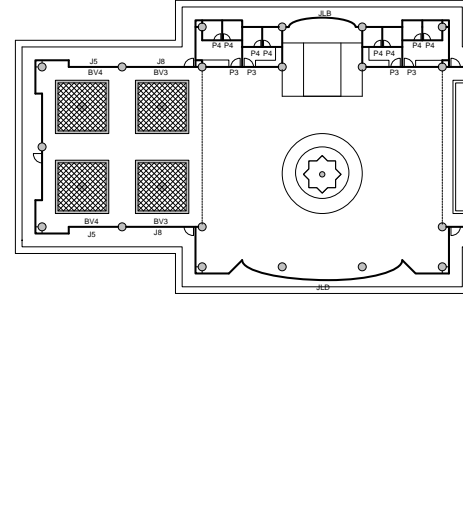 & Lantai 3 & $\begin{array}{l}\text { Yudisium } \\
\text { tingkat fakultas } \\
\text { Penerimaan } \\
\text { kunjungan } \\
\text { sekolah } \\
\text { Perkuliahan } \\
\text { (2 ruang kelas) }\end{array}$ & $\begin{array}{l}\text { Rapat } \\
\text { dosen } \\
\text { dan } \\
\text { karyawan } \\
\text { Rapat } \\
\text { kegiatan } \\
\text { akademik } \\
\text { Seminar } \\
\text { nasional }\end{array}$ & $\begin{array}{l}\text { Ospek } \\
\text { mahasiswa } \\
\text { baru } \\
\text { Upacara } \\
\text { dies natalis } \\
\text { Syawalan } \\
\text { keluarga } \\
\text { besar } \\
\text { fakultas } \\
\text { Seminar } \\
\text { nasional } \\
\text { Seminar } \\
\text { internasional }\end{array}$ & $\begin{array}{l}\text { Memerlukan } \\
\text { sarana lift }\end{array}$ \\
\hline
\end{tabular}

Sumber data: Observasi Lapangan.

Gambar 3. Analisis Okupasi Gedung KPLT FT UNY

Lantai satu dan lantai dua gedung KPLT FT UNY pada dasarnya dilihat dari fungsi dan okupasinya tidak memerlukan sarara lift. Dari jumlah okupasi masih sesuai rancangan awal, tidak ada penambahan yang berarti dari jenis fungsinya. Sementara dilihat dari dayaguna juga relatif masih dibawah $60 \%$. Namun lantai tiga terjadi ragam okupasi, selain itu pada lantai tiga gedung KPLT yang berfungsi sebagai ruang pertemuan (aula), sebagai obyek observasi utama okupasi gedung, menunjukkan karakteristik yang beragam antara lain yaitu:

1. Pada acara yudisium yang dilaksanakan setiap bulan, okupasi terdiri mahasiswa dan pimpinan fakultas berjumlah sekitar 100 orang, fenomena perilaku normal, tidak menuntut sarana khusus untuk mendukung kegiatan. Daya guna ruang pada acara yudisium sekitar $30 \%$.

2. Pada acara kunjungan sekolah yang terjadi maksimal lima kali sebulan, okupasi terdiri siswa, guru dan pimpinan fakultas jumlah okupasi menjapai 300 orang. Fenomena perilaku yang terjadi pada acara kunjungan sekolah termasuk normal.
Daya guna ruang pada acara kunjungan sekolah sekitar $50 \%$.

3. Pada acara ospek mahasiswa baru yang terjadi setahun sekali, okupasi adalah mahasiswa baru, panitia ospek dan instruktur, sementara okupasi sarana hampir tidak ada (mahasiswa duduk di lantai). Jumlah okupasi acara ospek termasuk tinggi sekitar 1000 orang, daya guna ruang mencapai $100 \%$ lebih. Fenomena perilaku yang terjadi pada acara opek tidak terlalu beragam karena aktifitasnya tidak lebih tiga kegiatan, sehingga tidak memerlukan daya dukung sarana khusus.

4. Pada acara rapat akademik dosen dan karyawan yang terjadi sepuluh kali dalam setahun, okupasi adalah dosen, karyawan dan pimpinan, sementara okupasi sarana utama kursi dan meja snack. Jumlah okupasi acara rapat akademik sekitar 300 orang, daya guna ruang mencapai $60 \%$ lebih. Fenomena perilaku yang terjadi pada acara rapat akademik tidak terlalu beragam karena aktifitasnya tidak lebih tiga kegiatan, sehingga tidak memerlukan daya dukung sarana khusus. 
5. Pada acara upacara ulang tahun institusi (dies natalis) setiap tahun, okupasinya adalah dosen, karyawan, pimpinan, mahasiswa, tenaga pensiunan, katering, musik, tarian dan tamu khusus, sedangkan okupasi sarana mencakup: kursi, meja snack, meja katering, pecah belah, makanan berat, makanan ringan, minuman, dan peralatan acara. Jumlah okupasi acara upacara ulang tahun institusi sekitar 800 orang, daya guna ruang mencapai sekitar 90\%. Fenomena perilaku yang terjadi pada acara upacara ulang tahun institusi beragam karena aktifitasnya yang beragam, sehingga memerlukan daya dukung sarana khusus.

6. Pada acara perayaan syawalan keluarga fakultas yang terjadi setiap tahun, okupasinya adalah dosen, karyawan, pimpinan, mahasiswa, tenaga pensiunan, anak-anak, ibu-ibu, katering, musik, tarian dan tamu khusus, sedangkan okupasi sarana mencakup: kursi, meja snack, meja katering, pecah belah, makanan berat, makanan ringan, minuman, dan peralatan acara. Jumlah okupasi acara upacara ulang tahun institusi sekitar 700 orang, daya guna ruang mencapai sekitar 90\%. Fenomena perilaku yang terjadi pada acara syawalan keluarga fakultas beragam karena aktifitasnya yang beragam, sehingga memerlukan daya dukung sarana khusus.

Pada awal rancangan, kegiatan makan bersama di lantai dua, namun demikian tuntutan praktis telah disepakati bersama bahwa daya tarik pertemuan itu termasuk hidangan itu sendiri. Kebutuhan mendesak adanya sarana perabotan dan bahan makanan yang harus diangkut ke lantai tiga. Kekuatan manusia pada umumnya untuk naik membawa barang ke lantai tiga rerata 10 trip, dan fakta yang terjadi ada sekitar 50 sampai 100 trip lebih, sehingga sangat diperlukan sarana lift.

Kapasitas lift 10 orang cukup efektif, karena lift cenderung berfungsi untuk angkutan ke lantai tiga. Lift penumpang yang dipilih daripada lift barang yang lebih diperlukan karena mengantisipasi fungsi yang beragam. Pada acara syawalan dan dies akan lebih terasa perlunya lift barang, namun ketika ada okupasi laten yang diundangkan wajib bagi gedung bertingkat, maka lift wajib ada untuk melayani difabel. Sementara institusi juga mengakomodasi mantan dosen dan karyawan untuk tetap dalam satu keluarga besar yang selalu diundang dalam acara dies dan syawalan. Mantan tenaga (pensiunan) tentu saja banyak yang sudah tua yang memerlukan kenyamanan untuk masuk ke ruang pertemuan, maka lift sangat diperlukan.

Letak lift berdasar optimasi analisis paling sesuai ada di sisi gedung depan bagian timur, karena mudah dinenal dan tidak terganggu strutur jaringan. Ruangan tersebut juga bebas fungsi utama kantor (dari lantai satu ke lantai dua sebagai hall). Kekurangannya karena harus melubangi struktur lantai satu dan lantai dua. Namun diliha dari konstruksinya tidak mempengaruhi kekuatan struktur. Hal ini karena struktur lantai gedung dibuat rusuk dengan modul 2,5 m x $25 \mathrm{~m}$. Hanya yang membuat bising adalah pada waktu pengerjaan.

Struktur pendukung lift yang paling sesuai untuk gedung adalah struktur baja IWF karena konstruksi merupakan tambahan dari gedung lama. Sementara untuk dinding pelingkupnya dapat menggunakan GRC, ACP atau bahan komposit dari plastik. 


\section{SIMPULAN}

Berdasarkan pembahasan di atas teramati bahwa kapasitas lift untuk gedung KPLT FT UNY adalah lift penumpang untuk 10 orang, dengan dua pintu membuka ke samping; letak lift gedung KPLT FT UNY yang sesuai dengan visibilitas, aksesibilitas dan bebas hambatan struktur

\section{DAFTAR RUJUKAN}

Brubaker, W. (2008). Planning and Designing Schools, McGraw-Hill Companies, Inc.

BNNP. (2011). Standar Sarana dan Prasarana Pendidikan Tinggi, Kemdikbud Jakarta.

Dibner, D. R. (2015). Building Additions Design. New York: Mc Graw-Hill Book Company.

Hartono Poerbo. (2012). Utilitas Bangunan, Penerbit Djambatan, Jakarta.

Julistiono. (2013). Desain Lift pada Bangunan Bertingkat. Jurnal Teknik Sipil dan Arsitektur, 11(2), 81-94. adalah di sisi depan sebelah timur ruang hall; struktur pendukung lift yang sesuai untuk gedung KPLT FT UNY adalah struktur baya karena merupakan konstruksi tambahan, sedangkan untuk pelingkupnya menggunakan GRC, ACP atau bahan komposit dari plastic.

Fakultas Teknik UNY. 2005. Dokumen Gambar Perencanaan Gedung KPLT.

https://www.google.co.id/search?q=gambar +lift\&newwindow.

Prihadi, W. R., \& Pratama, G. N. I. P. Konfigurasi Batang Pada Perancangan Rangka Atap Bambu. INERSIA, 12(2), 173-183.

Thiagarajan and Semmel. (1974). Research and Development 4D, Indiana Polis USA. 